\title{
O OLHAR DA MEDUSA: \\ COISIFICAÇÃO E RECONFIGURAÇÕES POLÍTICAS POR MEIO DO ENSINO DA ARTE E PRÁTICA CÊNICA
}

\section{The Medusa's sight: reification and politics reconfiguration trough art teaching and scenic practice}

Henrique Bezerra de Souza*

Universidade do Estado de Santa Catarina - UDESC

Resumo: O artigo parte de uma preocupação a respeito de um possível processo de coisificação dos indivíduos e de suas relações. Para investigar esta questão, toma como ponto de partida a ideia de capitalismo como religião apresentada por Walter Benjamin e, por meio deste pensamento, aponta a influência que o capital pode ter na construção subjetiva dos sujeitos, bem como possíveis transgressões para este processo através do ensino da arte.

Palavras-chave: subjetividade, arte, ensino.

Abstract: The article is based on a concern about a possible process of reification of individuals and their relationships. In order to investigate this question, it takes as its starting point the idea of capitalism as a religion presented by Walter Benjamin and, through this thought, points out the influence that capital can have on the subjective construction of subjects, as well as possible transgressions for this process through art teaching.

Keywords: subjectivity, art, teaching. 
A mitologia grega conta a história de uma figura mitológica chamada Medusa. Sua imagem é representada por uma mulher com cabelos de serpente, pele escamada e semblante petrificante. Seu olhar fazia com que todos que a observassem diretamente fossem rapidamente transformados em pedra, estátuas de si mesmos. A pele e a carne que antes habitavam os corpos davam lugar a uma rocha frágil, casca vazia que tão logo recebesse um impacto mais forte se quebraria. Assim, o que antes fora um sujeito tornava-se então um objeto, uma coisa.

A despeito da origem mitológica, creio que, em certa medida, este olhar petrificante ainda ocorre em alguma escala na sociedade contemporânea. Se hoje não há a possibilidade de transformar a pele em pedra, ainda há a capacidade de coisificar os sujeitos, retirar suas características individuais, maleáveis, únicas e transformá-los em cascas vazias, representações de si mesmos que, aparentemente, deixam de ser cobertas pelo estado de direito. Nesta perspectiva, corre-se o risco de inferir que, vistos como coisas que são, poderiam ser quebrados, amassados, trocados, cortados, abertos, fechados, descartados, substituídos, espancados sem que haja um pensamento prévio sobre tais ações, pois elas não estariam sendo realizadas sobre um sujeito, mas sobre uma coisa.

Muito embora esta afirmação inicial possa parecer demasiadamente cruel, ela encontra eco em diversas notícias ${ }^{1}$ veiculadas ao longo do tempo. Não obstante, Achille Mbembe (2006) parece reforçar tal pensamento ao refletir sobre o que seria a soberania. De acordo com o autor, ela consiste na capacidade e no poder de decidir quem pode viver e quem deve morrer, apontando assim uma ideia de necropolítica. Tal ideal estrutura diversos mecanismos de estratificação social que são utilizados para estabelecer relações entre ideias como as de raça, o binômio colonizados e colonizadores, o poderio econômico, etc. Em suas palavras: "[...] a soberania é a capacidade para definir quem tem importância e quem não tem, quem está desprovido de valor e pode ser facilmente substituído e quem não"2. (MBEMBE, 2006, p. 46, Tradução nossa). Muito embora Mbembe baseie suas reflexões principalmente no contexto africano, seus pensamentos podem ser facilmente transpostos para outros locais. Nesta perspectiva, creio que a Medusa mitológica não exista hoje, mas temo que seu olhar coisificante ainda atue em alguma medida nas relações políticas e afetivas entre os indivíduos.

A coisificação não se detém somente nos sujeitos, mas passa a afetar instâncias, afetos e pensamentos

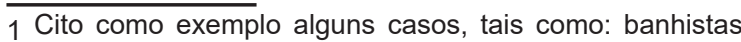
de Florianópolis continuam aproveitando a praia mesmo com a presença do corpo de um nordestino assassinado (TORRES, 2016), dois jovens espancam um ambulante do metrô de São Paulo até a morte (PAGNAN, 2016), mais de 30 homens estupram uma jovem de 17 anos no Rio de Janeiro (RAMALHO, 2016).

2 "[...] la soberania es la capacidade para definir quién tiene importância y quién no la tiene, quién está desprovisto de valor y puede ser facilmente sustituible y quién no". 
que, por si, deveriam ser maleáveis e múltiplos, mas sofrem exercícios constantes para que adquiram as mesmas características rígidas de uma estátua. Em outras palavras, a Medusa contemporânea parece travar um exercício contínuo buscando impor formas corretas e padronizadas de se pensar e ser no mundo, fazendo com que quaisquer transgressões se tornem alvo de seu olhar. Tendo em mente tais apontamentos, este artigo visa refletir sobre as formas e os ecos das ações que poderiam gerar esta coisificação. A partir destas investigações, almeja então apontar rotas de fuga através do ensino da arte e da prática cênica que, em alguma medida, auxiliem na desconstrução deste olhar.

\section{O Capitalismo como religião e o sufocamento de subjetividades}

Tomo como primeiro indício desta coisificação a ideia de capitalismo como religião proposta por Walter Benjamin (2013). De acordo com o filósofo, a lógica capitalista está a serviço das mesmas preocupações e inquietações que as religiões visam responder. Para defender tal pensamento, Benjamin aponta três características que aproximam o sistema desta estrutura religiosa, estas são:

Em primeiro lugar, o capitalismo é uma religião puramente cultual, talvez até a mais extremada que já existiu. Nele, todas as coisas só adquirem significado na relação imediata com o culto; ele não possui nenhuma dogmática, nenhuma teologia. Sob esse aspecto, o utilitarismo obtém sua coloração religiosa. [...] um segundo traço do capitalismo: a duração permanente do culto. O capitalismo é a celebração de um culto sans rêve et sans merci [sem sonho e sem piedade]. Para ele, não existe 'dias normais', não há dia que não seja festivo no terrível sentido da ostentação de toda a pompa sacral, do empenho extremo do adorador. Em terceiro lugar, esse culto é culpabilizador. O capitalismo presumivelmente é o primeiro caso de culto não expiatório, mas culpabilizador. [...] Uma monstruosa consciência de culpa que não sabe como expiar, lança mão do culto, não para expiar essa culpa, mas para torná-la universal, para martelá-la na consciência [...] (BENJAMIN, 2013, p. 17)

Analisando estas características, podem-se perceber três aspectos importantes. Primeiramente, se as coisas só obtêm significado na medida em que estão ligadas ao culto/sistema, é possível inferir que o valor de suas existências está prioritariamente ligado ao valor de troca que elas têm dentro dele. Em segundolugar, por ser contínuo, não ocorrer apenas em momentos eventuais, mas permanentemente, este processo infiltra-se e contamina praticamente todas as relações que ocorrem entre os indivíduos. Por fim, a culpa contínua gera uma sensação de pouca dedicação ao culto/sistema, sendo sempre necessário fazer mais, trabalhar mais, ganhar mais, na tentativa de agregar a si mesmo cada vez um maior valor de troca. 
Observo nestes apontamentos os indícios da coisificação dos seres e do mundo, visto que, na religião capitalista a que se refere Benjamin, a existência passa a estar condicionada principalmente ao valor de troca e a luta para aumentá-lo. Nesta perspectiva, incorre-se no risco de se criar uma tendência a enxergar o mundo, seus habitantes e suas eventuais criações, apenas como mercadorias. Adotar esta visão fortalece um movimento que faz com que o ter se torne o novo ser. Assim sendo, não ter significaria por consequência não ser e, ao não ser, o sujeito se descaracterizaria e tomaria o estado de coisa que poderia ser manipulada de acordo com os desejos daqueles que seriam, sob a ótica do sistema, sujeitos.

Esta influência dos fatores econômicos na formação do sujeito e da subjetividade pode seraprofundada quando se observa o pensamento de Karl Marx. Apesar de alguns autores ${ }^{3}$ afirmarem que Marx não se debruçou sobre a subjetividade, visto que seus escritos são prioritariamente econômicos e podem dar a entender que as manifestações subjetivas dos seres são meras consequências das determinações econômicas e materiais, creio que adotar tal postura seria aplainar seu pensamento a um determinismo e uma objetividade excessivamente simplistas. A meu ver, o pensamento

\footnotetext{
3 Não desenvolverei tal questão neste texto para não fugir do foco do artigo. Porém, caso o leitor tenha interesse e deseje mais informações sobre a discussão da subjetividade no âmbito do marxismo, sugiro verificar os estudos de Silveira (2002) e Chagas (2013).
}

marxista aponta um sujeito em processo de autodeterminação, condicionado sim pelas questões econômicas e materiais, mas que, em alguma medida, as modifica e, com isso, pode proporcionar novos espaços subjetivos mediante a reestruturação dos fatores econômicos e materiais. Esta visão também é partilhada por Eduardo Chagas (2013) quando afirma que:

Marx não compreende a subjetividade como um simples reflexo das determinações da base econômica, como um mero produto do econômico, e sim como um componente inseparável dos processos de formação da vida humana. O seu pensamento não pode ser reduzido a um objetivismo, a um mero determinismo econômico, unilateral, visto que a objetividade é impensável sem uma íntima correspondência com a subjetividade. Não há, para ele, objeto sem sujeito, como não há sujeito sem objeto. Nenhum dos polos dessa relação, sujeito e objeto, é posto como um dado a priori; eles se constituem na relação. [...] E é nesse processo de autoconstrução que se criam novas formas de objetivação, que possibilitam, por sua vez, novas formas de subjetivação. 0 que Marx quer mostrar é, na verdade, que a subjetividade não é nem uma instância própria, autônoma, independente, abstrata, nem posta naturalmente, dada imediatamente ao indivíduo, mas construída socialmente, produzida numa dada formação social, num determinado tempo histórico. (CHAGAS, 2013, p. 65)

Ocorre que, ao adotar a construção da subjetividade sob o viés de uma relação 
temporal e histórica, condicionada socialmente, pode-se inferir que o sistema econômico de fato impacta a formação subjetiva dos sujeitos. No caso em questão, na ótica do capitalismo como religião, o acúmulo de capital poderia então influenciar aqueles que serão considerados sujeitos e aqueles que não serão. Temse aí uma espécie de necropolítica da subjetividade, determinando aqueles que seriam sujeitos e aqueles que seriam coisas. O problema é que, desse modo, cria-se um círculo vicioso de características macabras na medida em que os considerados como sujeitos por este sistema, ao dominarem a visão predominante de mundo, reforçam aspectos subjetivos que lhes beneficiem na tentativa de manter o próprio status, passando assim a edificar padrões de subjetividade dominantes que dificultam o reconhecimento de qualquer transgressão a norma, de outras formas de existência. Esta negação das diferenças tende a se traduzir em ações contra indivíduos e grupos pertencentes às minorias étnico-raciais, de gênero, econômicas, etc.

Tal processo pode fazer com os que não são considerados sujeitos pelo sistema tomem o estado de coisa, passando a serem vistos e tratados como tal. Desse modo, como abordado no início deste artigo, cria-se uma espécie de imaginário que, à primeira vista, aparentemente retira estes indivíduos/ coisa da cobertura do estado de direito. Tal pensamento se infiltra em diversas frases veiculadas em mídias sociais e entrevistas, tais como: "Bandido bom é bandido morto"; "Direitos humanos para humanos direitos"; "E nordestino lá é gente?"4. Nestes exemplos, é interessante observar as categorias de humanos direitos e gente, visto que carregam na frase um ato excludente, na medida em que afirmam que alguns indivíduos devem ser considerados como tais, enquanto outros não. Do mesmo modo, a primeira frase parece defender que aquele que se encaixar na categoria bandido imediatamente deveria perder um dos principais fundamentos garantidos por lei aos sujeitos: o direito à vida. A questão preocupante que este modo de pensar assinala é: quem ou o que determina em qual categoria os seres se encaixam?

Tendo a crer que uma das respostas possíveis para esta pergunta seria o próprio capital, no momento em que promove formas de tratamento diferenciadas (e aqui se incluem o modo como notícias são veiculadas, os encaminhamentos jurídicos, a atribuição ou não de culpa, etc.) para indivíduos que tenham realizado a mesma ação. Nesta ótica, os que por ventura estão excluídos do modelo de subjetividade legitimado pelo sistema tendem a tornarse alvos de ações que dificilmente

\footnotetext{
4 Escolhi fazer referência a esta região específica do país por dois fatores: O primeiro se baseia na forte onda de comentários ofensivos que invadiu as redes sociais, principalmente no ano de 2014, como pode ser consultada nas notícias Marins (2017), Cardozo (2017), Guimarães (2017), entre outras. O segundo se deve ao fato de ser natural da região e já ter vivenciado situações como a citada acima.
} 
seriam realizadas entre aqueles que 0 padrão dominante considera sujeitos. A lei parece não os contemplar, reiterando assim o que já alertava Zygmunt Bauman:

[...] a lei limita sua preocupação com o marginalizado/excluído para mantêlo fora do domínio governado pela norma que ela mesmo circunscreveu. A lei atua sobre essa preocupação proclamando que o excluído não é assunto seu. Não há lei para ele. (BAUMAN, 2005, p. 43)

\section{A Coisificação nas relações entre os sujeitos}

Este olhar coisificante não se atém à condição de sujeito em si, mas trespassa também para as relações afetivas. Tomando como exemplo a própria ideia do amor, nota-se como ela corre o risco de ser afetada e ser encarada sob uma ótica que prioriza o cálculo e o interesse. Erich Fromm (2000), em seu livro A Arte de Amar, já alertava para o risco de uma possível confusão entre o ato de buscar o amor e a necessidade de ser amado. De acordo com o autor, na tentativa de sanar esta necessidade e se tornar um objeto amável, os indivíduos buscam somar características ao próprio ser que os tornariam atraentes. Neste processo, são criados diversos estratagemas que, em sua visão, os distanciariam do amor. Fromm aponta que um destes estratagemas, "[...] especialmente utilizado pelos homens, é ter sucesso, ter todo o poder e riqueza que a sua posição social permitir" (FROMM, 2000, p. 11). Com isso, se cria uma espécie de mercado da personalidade e, o que deveria ser um sentimento livre de determinações econômicas, passa a ser coisificado e contabilizado, o que antes eram sujeitos tornam-se novamente indivíduos-coisas expostos na vitrine dos relacionamentos. Como assinala o autor:

Toda nossa cultura se baseia no apetite da compra, na ideia de uma troca mutuamente favorável. A felicidade do homem moderno consiste na sensação de olhar vitrinas das lojas e em comprar tudo quanto esteja em condições de comprar, quer a dinheiro, quer a prazo. Ele (ou ela) encara as pessoas de maneira semelhante. (FROMM, 2000, p. 12)

Seguindo uma linha de raciocínio semelhante, Bauman (2004) aponta a liquidez das relações afetivas contemporâneas. Para o autor, os sujeitos possuem um desejo intenso de se relacionarem afetivamente, mas, por vezes, o fazem com uma margem de segurança, visto que, ao se comprometerem com algo fixo e sólido como uma relação, estariam fechando as portas para outras oportunidades afetivas que, para eles, poderiam ser melhores do que a atual. Nesta perspectiva, os relacionamentos são tratados com uma espécie de liquidez, uma aproximação que visa sanar a solidão, mas que não seja tão intensa a ponto de privar o sujeito de adquirir algo que, por ventura, ele considere melhor. Nas palavras de Bauman:

$\begin{array}{lll}\text { Consideradas defeituosas ou } & \text { ou } \\ \text { não plenamente 'satisfatórias', } & \text { as }\end{array}$ 
mercadorias podem ser trocadas por outras, as quais se espera que agradem mais, mesmo que não haja um serviço de atendimento ao cliente e que a transação não inclua a garantia de devolução do dinheiro. Mas, ainda que cumpram o que delas se espera, não se imagina que permaneçam em uso por muito tempo. Afinal, automóveis, computadores ou telefones celulares perfeitamente usáveis, em bom estado e em condições de funcionamento satisfatórias, são considerados, sem remorso, como um monte de lixo no instante em que 'novas e aperfeiçoadas versões' aparecem nas lojas e se tornam o assunto do momento. Alguma razão para que as parcerias sejam consideradas uma exceção à regra? (BAUMAN, 2004, p. 14)

Creio que esta liquidez e velocidade nas trocas afetivas são possíveis mediante este olhar que aproxima tudo da lógica da mercadoria. Com isso, não só os sujeitos passam a ver uns aos outros como coisas, mas as próprias relações adquirem um tom passageiro, coisificado, facilmente substituíveis. Retomando a metáfora do início deste artigo, a Medusa contemporânea pode não ter um corpo físico ou uma representação própria no mundo de hoje, porém, seu olhar coisificante ainda é bem presente na religião capitalista, na medida em que passa a denegar o real valor e a existência dos afetos e dos sujeitos, enquanto enfatiza seus valores de troca, buscando transformar tudo e todos em coisas, em mercadorias.

Giorgio Agamben (2007) alerta para esta característica da religião capitalista. Ela retira dos sujeitos a potência de uso real do mundo, separa dos indivíduos as diversas possibilidades de uso, visto que, busca transformar tudo em objeto de consumo, mercadoria. É como se o capitalismo como religião consagrasse tudo que toca, entendendo como consagrar o fato de lançar o que for tocado para a esfera do sagrado, ou seja, lançá-lo ao domínio dos deuses, um local inalcançável que o retira do domínio e uso dos homens. As relações afetivas, invenções, ideias, sexualidade, o próprio corpo humano são separados de si mesmos, seu uso não é mais livre e fica condicionado, antes de tudo, pela lógica do consumo, na medida em que eles se tornam mercadorias.

Para que tal corrente seja quebrada, é necessário realizar o que Agamben chama de profanação. Para ele, profanar seria retirar algo da esfera do sagrado e colocá-lo no domínio e uso dos homens. Em outras palavras, seria questionar uma maneira estabelecida e sacralizada de ser no mundo, ao mesmo tempo em que se reconfigura novos usos para o que estivesse sacralizado. Tendo em mente este processo, creio que para fugir deste olhar coisificante que a Medusa contemporânea insiste em lançar, é necessário profanar a visão de sujeito que a religião capitalista tende a edificar. Tal ato poderia promover uma desconstrução dos modos de subjetividade e das relações políticas que, por ventura, estejam estabelecidos, e ampliaria os modelos de relação que 
os sujeitos podem desenvolver entre si.

Apontar caminhos concretos para este ato de profanação talvez não seja uma ação frutífera, tendo em vista que logo eles poderiam ser anulados e cooptados pelo sistema. Penso então que a solução é encontrar pistas, indícios de ações, novos usos para o que está sacralizado que sejam capazes de questionar o que está estabelecido e possam estimular formas distintas de ser, pensar e se relacionar. Este modo de ação transversal visa duvidar do padrão estabelecido, para que, assim, as dúvidas impliquem em ações originais e, neste processo, carreguem a possibilidade de apontar falhas e gerar rupturas no sistema vigente. Partindo deste ponto, creio que o ensino da arte possa ser uma destas pistas.

\section{O ensino da arte e a prática cênica como prática política}

A prática pedagógico-artística tem a capacidade de estimular outras formas de encarar o mundo. Tomando como centro da reflexão a prática cênica, observa-se que, por vezes, os objetos tendem a ser ressignificados, na medida em que seu uso não está obrigatoriamente vinculado a sua concepção original (como um exemplo simples pode-se pensar em um cabo de vassoura que se torna um cavalo, uma espada, uma bengala, um palito de dente...). Além disso, quer seja através de uma narrativa linear ou propostas estéticas mais fragmentadas, a prática cênica pode evidenciar e questionar padrões de existência que já estão estabelecidos e que, por vezes, passam desapercebidos pela naturalização do olhar cotidiano. Tais práticas podem ser exemplificadas nos pensamentos de encenadores como Brecht e Boal, bem como nas ações estimuladas por pesquisadores e grupos atuais, tais como: Márcia Pompeo Nogueira (2015) e suas reflexões sobre o Teatro em Comunidades, as performances realizadas pelo grupo paulista Desvio Coletivo, entre outros. Não obstante, tomando como exemplo a abordagem triangular ${ }^{5}$ no ensino da arte proposta por Ana Mae Barbosa (1995), a própria ação estética deixa de ser considerada como algo dado, mas é entendida como um longo processo, passando a ser contextualizada em sua origem e, por sua vez, questionada.

Estes encaminhamentos aparentemente simples induzem um certo descondicionamento do olhar. Estimulam atividades que, a meu ver, são importantes para promover fissuras nos padrões estabelecidos. Ao evidenciar modelos totalizantes e desenvolver outras formas de uso e relação com eles, ocorre um certo

\footnotetext{
5 A abordagem triangular é uma proposta pedagógica difundida principalmente por Ana Mae Barbosa, na qual a pesquisadora defende que o ensino da arte seja estimulado em três vias: criação artística, contextualização da ação artística, apreciação da ação artística. Assim, o aluno teria a oportunidade de passar por estas três etapas do processo e se relacionaria com as obras sabendo que ele mesmo pode ser um artista, bem como que tais obras têm um contexto histórico-social que as contamina esteticamente e, por meio disso, torna-se capaz de desenvolver as próprias relações e uma leitura pessoal das ações artísticas com as quais entra em contato.
} 
exercício de alteridade. Não falo da obra artística em si, finalizada, mas de seu processo, o transcorrer de seu desenvolvimento artístico-pedagógico pode estimular um olhar questionador, evidenciar as potencialidades dos sujeitos e das coisas, entendendo que, por mais que um modelo de ação seja o dominante, ele ainda o é, apenas, um dos modelos de ação possíveis.

Sob esta ótica, se aponta uma possível fuga do olhar coisificante, pois, assim como as questões e ressignificações que a prática cênica pode propor, apontam outras possibilidades de mundo, exercita-se a noção de que este olhar coisificante também é apenas uma possibilidade de se enxergar o mundo e os sujeitos, também é condicionado por um contexto determinado e, por sua vez, passível de ser questionado. Em síntese, é como se o ensino da arte carregasse uma potência política, fosse capaz de apontar subjetividades e relacionamentos possíveis que não são necessariamente os que vigoram na prática e, no momento em que os aponta, encoraja rupturas nos padrões vigentes.

Tendo tal pensamento em mente, é interessante observar as reflexões de Jacques Rancière sobre arte, política e seu potencial de reconfiguração de partilhas. De acordo com o filósofo, a política não seria o exercício do poder, mas as relações que os indivíduos estabelecem. Um tipo de ação paradoxal em que o indivíduo é, ao mesmo tempo, agente e matéria sobre a qual se age. Ação que pressupõe um processo não de dominação, mas de igualdade. Sua prática não visa corroborar os padrões vigentes, mas questionar a ordem estabelecida. Como lembra Rancière:
A política é a atividade que reconfigura os âmbitos sensíveis nos quais se definem os objetos comuns. Ela rompe a evidência sensível da ordem 'natural' que destina os indivíduos e os grupos ao comando ou à obediência, à vida pública ou à vida privada, votando-os sobretudo a certo tipo de espaço ou tempo, a certa maneira de ser, ver e dizer. (RANCIĖRE, 2014, p. 59,60 )

Ao refletir sobre o tema, Rancière aponta que, inicialmente, as relações que caracterizam a política foram construídas através da posse do logos, do direito à palavra. Esta característica comum aos indivíduos era partilhada de uma maneira específica, sua divisão não se dava através de uma igualdade aritmética, mas geométrica, fundamentada no potencial de bem comum que os sujeitos poderiam trazer à pólis. Contudo, tal erro de contagem carregava a possibilidade de gerar uma configuração que afastava o caráter igualitário da política e, devido a isto, a colocava em risco. Para ilustrar este pensamento, o filósofo se baseia nas ideias de Aristóteles e aponta como se dava esta distribuição. De acordo com ele:

[...] para a harmonia comum, coloca em proporção as parcelas da coisa comum possuídas por cada parte da 
comunidade à parcela que ela traz ao bem comum [...] Para que a pólis seja ordenada conforme o bem, é preciso que as parcelas da comunidade estejam em estrita proporção com a axia de cada parte da comunidade: ao valor que ela traz para a comunidade e ao direito que esse valor lhe dá de deter uma parte do poder comum. (RANCIÈRE, 1996, p. 21)

Esta ótica parece justificar que, devido a fatores ${ }^{6}$ previamente estabelecidos, alguns indivíduos possuam uma parcela maior do direito de fala, poder político, governo ou, no caso abordado neste artigo, o direito a serem considerados sujeitos. Ocorre que tal acepção comporta em si um paradoxo quando relacionado à ideia da política proposta por Rancière, visto que, na concretização prática de seu ato, favorece um processo de dominação e retira uma parcela da igualdade entre os indivíduos ao defender que uns detenham um direito natural. Em síntese, este modo de divisão estabelece formas de ver e lidar com o mundo ou, como denomina Rancière, partilhas do sensível que, neste caso, visam excluir uma parcela da população da prática política e das construções subjetivas. Como aponta o filósofo:

Os artesãos, diz Platão, não podem participar das coisas comuns porque eles não têm tempo para se dedicar a outra coisa que não seja seu trabalho. Eles não podem estar em outro lugar porque o trabalho não espera. A partilha do sensível faz ver

6 Acúmulo de capital, títulos, cargos, posses, local de nascimento... quem pode tomar parte no comum em função daquilo que faz, do tempo e do espaço em que essa atividade se exerce. (RANCIĖRE, 2009, p. 16)

Tendo isto em mente se faz necessária uma revisão das partilhas. Caso ela não ocorra, haverá uma manutenção deste processo que relega o comando e, por consequência, a edificação de um padrão subjetivo dominante àqueles que as atuais configurações políticas defendem que já deveriam possuí-lo.

$\mathrm{Na}$ rota de fuga que aponto, creio que o fortalecimento do ensino da arte pode trazer à tona manifestações estéticas que estariam desvinculados de uma única apreensão sensível. Ao promover leituras pessoais, exercícios de descondicionamento do olhar, é possível observar a possibilidade de um potencial político na prática artística, na medida em que, ao estimular partilhas do sensivel distintas, se favorece a criação de um tecido sensível dissensual. Ora, se a política deveria reconfigurar a noção de ordem natural, promover uma redistribuição de partilhas, a arte carrega este potencial quando realiza uma atitude semelhante ao redefinir assim possibilidades do visível e do dizível. Nesta acepção:

Arte e política têm a ver uma com a outra como formas de dissenso, operações de reconfiguração da experiência comum do sensível. Há uma estética da política no sentido de que os atos de subjetivação política redefinem o que é visível, o que se pode dizer dele e que sujeitos são capazes de fazê-lo. Há uma política 
da estética no sentido de que as novas formas de circulação da palavra, de exposição do visível e de produção dos afetos determinam capacidades novas, em ruptura com a antiga configuração do possível. (RANCIÈRE, 2014, p. 63)

Então, no momento em que o ensino da arte e, mais especificamente no caso tratado neste artigo, a prática pedagógica com ações cênicas propõem situações que estimulem um encontro discordante de percepções distintas, uma multiplicidade de manifestações sensíveis e maneiras de lidar com estes acontecimentos, observamse pontos que revelam seu potencial político, trazem à tona a possiblidade de apresentar este tecido sensível dissensual, ou seja, um ambiente que comporte as diferenças e não busque necessariamente apaziguá-las sob a máscara de um consenso universal forjado.

Entretanto, deve-se ter em mente que esta é uma possibilidade otimista, visto que, facilmente, as ações artísticas podem ser transformadas em produtos, tornarem-se alvo deste olhar coisificante e submetidas à lógica do consumo e da mercadoria. É por ter em mente este risco que chamo a atenção não para as manifestações artísticas em si, mas para seu processo pedagógico, pois, vejo em seu desenvolvimento o momento de exercício para exploração de outros possíveis que, talvez, possam ser praticados também nas relações políticas entre os sujeitos.
Retomandoametáforainicialdesteartigo, se a Medusa não pode ser confrontada por um olhar direto, mas através de uma olhadela invertida, talvez o ensino da arte e da prática cênica possam fazer com que se enxerguem os sujeitos e as coisas além deste olhar coisificante que predomina hoje. O exercício constante de gerar outros possíveis e o tecido dissensual que tal ato tende a fomentar poderia funcionar como este olhar indireto e, talvez, guiasse ações que paulatinamente reconfigurassem padrões políticos, subjetivos e afetivos, auxiliando a encaminhar um golpe na Medusa que nós enfrentamos hoje.

\section{Recebido em 25/07/2017}

Aceito em: 05/09/2017

\section{Referências Bibliográficas}

AGAMBEN, Giorgio. Profanações. São Paulo: Boitempo, 2007.

BARBOSA, Ana Mae. Arte-educação pós-colonialista no Brasil: aprendizagem triangular. Comunicação e educação, São Paulo, v. 2, p. 59 - 64, 1995.

BAUMAN, Zygmunt. Amor líquido: sobre a fragilidade dos laços humanos. Rio de Janeiro: Jorge Zahar, 2004.

BAUMAN, Zygmunt. Vidas desperdiçadas. Rio de Janeiro: Jorge Zahar, 2005.

BENJAMIN, Walter. 0 capitalismo como religião. São Paulo: Boitempo, 2013. 
CARDOZO, Eduardo. MPF em Canoas denuncia usuária do Facebook por discriminação contra nordestinos. Gaúcha. Disponível em: <http://gaucha. clicrbs.com.br/rs/noticia-aberta/mpfem-canoas-denuncia-usuaria-dofacebook-por-discriminacao-contranordestinos-167522.html> Acesso em: 26/03/2017.

CHAGAS, Eduardo Ferreira. O pensamento de Marx sobre a subjetividade. Revista Trans/Form/ Ação, Marília, UNESP, v. 36, n. 2, p. 63 - 84, Maio/Agosto, 2013.

FROMM, Erich. A arte de amar. São Paulo: Martins Fontes, 2000.

GUIMARÃES, Nathália. Campanha expõe preconceito sofrido por nordestinos. LeiaJá. Disponível em: <http://www.leiaja.com/ noticias/2016/10/08/campanha-expoepreconceito-sofrido-por-nordestinos/> Acesso em: 26/03/2017.

\section{MARINS, Lucas Gabriel. Usuários} ofendem nordestinos nas redes sociais. Gazeta do Povo. Disponível em: <http://www.gazetadopovo.com. $\mathrm{br} / \mathrm{vida}$-e-cidadania/usuarios-ofendemnordestinos-nas-redes-sociaiseekhy07hh6yxh9vhg9jcscy1a> Acesso em: 26/03/2017.

MBEMBE, Achille. Necropolítica. España: Melusina, 2006.

NOGUEIRA, Marcia Pompeo. Ventoforte no teatro em comunidades. Florianópolis: Letras Contemporâneas,
2015.

PAGNAN, Rogério. Assassinos de ambulante serão levados para - 'presídio de famosos' em SP. Folha de São Paulo. Disponível em: $\quad<$ http://www1.folha.uol.com. $\mathrm{br} / \mathrm{cotidiano} / 2016 / 12 / 1845477$ assassinos-de-ambulante-seraolevados-para-o-presidio-de-famososem-sp.shtml> Acesso em: 26/03/2017.

RAMALHO, Guilherme. "Quando acordei tinha 33 caras em cima de mim", diz menina que sofreu estupro coletivo. O Globo. Disponível em: <http://oglobo.globo.com/rio/quandoacordei-tinha-33-caras-em-cima-demim-diz-menina-que-sofreu-estuprocoletivo-19380492> Acesso em: 26/03/2017.

RANCIĖRE, Jacques.

desentendimento: política e filosofia. São Paulo: Editora 34, 1996.

RANCIĖRE, Jacques. A partilha do sensível. São Paulo: Editora 34, 2009. RANCIĖRE, Jacques. O espectador emancipado. São Paulo: Martins Fontes, 2014.

SILVEIRA, Maria Lídia Souza da. Algumas notas sobre a temática da subjetividade no âmbito do marxismo. Revista Outubro, n. 7, p. $103-113$, 2002.

TORRES, Aline. Corpo fica por duas horas estendido em praia de Florianópolis. Estadão. Disponível em: <http://brasil.estadao.com.br/ noticias/geral,corpo-fica-por-duashoras-estendido-em-praia-deflorianopolis, 10000013347> Acesso em: 26/03/2017. 